\title{
Facilitated aortic root substitution after aortic valve replacement: Technique and results of the prosthesis-sparing operation
}

\author{
Nicola Luciani, MD, ${ }^{\mathrm{a}}$ Amedeo Anselmi, MD, ${ }^{\mathrm{a}}$ Raphael de Geest, MD, ${ }^{\mathrm{b}}$ Franco Glieca, MD, ${ }^{\mathrm{a}}$ and \\ Gianfederico Possati, MD, ${ }^{\mathrm{a}}$ Rome, Italy, and Aalst, Belgium
}

Cardiac reinterventions are increasingly frequent; among these, reoperations on the aortic root are particularly demanding. ${ }^{1-3}$ Patients may have aortic valve replacement (AVR) complication (ie, ascending aortic pseudoaneurysm) or evolution toward frank aortic disease (aortic root \pm ascending aortic aneurysm). Our current inability to reliably predict the course of borderline ascending aortic dilatation at the time of AVR in patients without Marfan disease may account for a significant number of cases presenting electively for this redo surgery.

We discuss a modified Bentall procedure for replacement of the aortic root and ascending aorta in 4 patients in whom a late aneurysm of the aortic root, ascending aorta, and arch (1 case) developed. A well-functioning aortic valvular prosthesis was present, which was spared and left in place. The early results, advantages, and disadvantages are discussed.

\section{CLINICAL SUMMARY}

Thirteen patients who had elective reoperation on the aortic root after previous AVR between 2004 and 2008 at the Catholic University of Rome were retrospectively selected from our electronic database. Among these, 4 patients received a prosthesis-sparing operation.

In all patients, cardiopulmonary bypass was instituted using cannulation of the right femoral artery and vein and the right jugular vein; in 3 patients the extracorporeal circulation was initiated before resternotomy to decompress the heart and ascending aortic aneurysm. The valvular prosthesis was evaluated by intraoperative transesophageal echocardiography to disclose any paravalvular leak or pannus overgrowth at the ventricular side. After aortic crossclamping, the ascending aortic aneurysm was opened, and the aortic prosthesis was inspected to rule out thrombus, pannus overgrowth, or any malfunction. Myocardial protection was

\footnotetext{
From the Division of Cardiac Surgery, Catholic University, ${ }^{\mathrm{a}}$ Rome, Italy; and Division

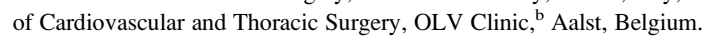
Disclosures: None.

Received for publication Jan 31, 2009; accepted for publication April 11, 2009; available ahead of print June 1, 2009.

Address for reprints: Amedeo Anselmi, MD, Division of Cardiac Surgery, Catholic University, Largo A. Gemelli, 8, 00168 Rome, Italy (E-mail: amedeo.anselmi@ alice.it).

J Thorac Cardiovasc Surg 2010;139:785-7

$0022-5223 / \$ 36.00$

Copyright (c) 2010 by The American Association for Thoracic Surgery

doi:10.1016/j.jtcvs.2009.04.009
}

accomplished by cold crystalloid Custodiol (Köhler Chemie, Alsbach-Hänlein, Germany) cardioplegia. The aortic wall was trimmed 3 to $4 \mathrm{~mm}$ above the sewing ring of the valvular prosthesis, and the coronary ostia were totally isolated. Interrupted pledgeted mattress sutures (3-0 braided polyester sutures) were passed from outside the aortic wall through the prosthetic ring and a Dacron tube graft of appropriate size. Graft size was selected to optimally fit the prosthesis sewing ring. The graft was then parachuted into position, and the sutures were tied. In all patients, an additional continuous suture was passed through the trimmed aortic edge and the tube graft to optimize the hemostasis. The suture line was checked by forced instillation of heparinized blood, and the coronary ostia were finally anastomosed to the graft as usual (Figure 1, $A, B$ ). Finally, the distal anastomosis was performed.

The cases are detailed in Table 1. Conversion to composite graft implantation was not required in any of the patients. The mean cardiopulmonary bypass time was $259.5 \pm 100$ minutes, and the aortic crossclamp time was $171.5 \pm 49.9$ minutes. There was no severe bleeding intraoperatively or postoperatively. The mean intensive care unit stay was 6 days. There was 1 operative death due to insufficient myocardial protection and reentry lesion of a patent left internal thoracic artery graft, leading to severe left ventricular dysfunction and multiorgan failure in a patient undergoing concomitant redo coronary
A

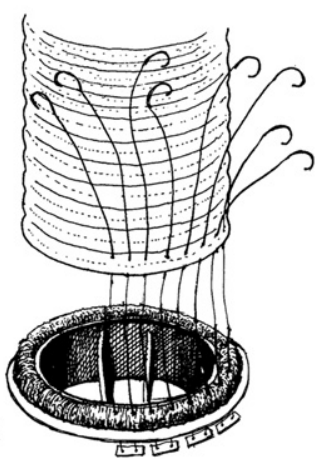

B

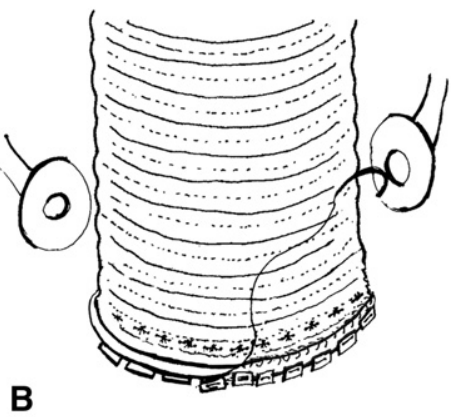

FIGURE 1. A, Interrupted mattress pledgeted sutures are passed through the aortic annulus and prosthetic sewing ring. The sutures are passed through the end of a Dacron tube graft. B, After tying the stitches, a continuous suture is passed through the trimmed aortic edge and the tube graft. The hemostasis is checked, and the coronary arteries are reimplanted on the tube graft according to the standard button technique. 
TABLE 1. Details of the four cases taken into analysis

\begin{tabular}{|c|c|c|c|c|c|c|c|}
\hline & $\begin{array}{c}\text { Previous } \\
\text { operation(s) }\end{array}$ & Diagnosis & Reoperation & $\begin{array}{c}\text { Age at } \\
\text { reoperation (y) }\end{array}$ & $\begin{array}{c}\text { CPB } \\
\text { time/arrest } \\
\text { time (min) }\end{array}$ & $\begin{array}{l}\text { Crossclamp } \\
\text { time (min) }\end{array}$ & $\begin{array}{c}\text { Postoperative } \\
\text { course }\end{array}$ \\
\hline Case 1 (S.F.F.) & AVR & Aortic root aneurysm & Modified Bentall & 68 & $186 /-$ & 130 & Regular \\
\hline Case 2 (F.V.) & AVR & $\begin{array}{l}\text { Aortic root and } \\
\text { proximal arch } \\
\text { aneurysm, tricuspid } \\
\text { regurgitation }\end{array}$ & $\begin{array}{l}\text { Modified Bentall }+ \\
\text { hemiarch } \\
\text { replacement }+ \text { TVP }\end{array}$ & 59 & $215 / 22$ & 148 & $\begin{array}{l}\text { Atrial fibrillation, } \\
\text { acute renal } \\
\text { failure } \\
\text { (recovered) }\end{array}$ \\
\hline Case 3 (P.L.) & $\begin{array}{l}\quad \text { AVR - } \\
\text { supracoronary } \\
\text { ascending aortic } \\
\text { replacement, } \\
\text { aortic fenestration }\end{array}$ & $\begin{array}{l}\text { Aortic root, arch, and } \\
\text { thoracoabdominal } \\
\text { aneurysm, chronic } \\
\text { type A dissection, } \\
\text { Marfan }\end{array}$ & $\begin{array}{l}\text { Modified Bentall } \\
\text { (open distal } \\
\text { anastomosis) }\end{array}$ & 72 & $230 / 17$ & 162 & Regular \\
\hline Case 4 (D.A.) & $\mathrm{AVR}+\mathrm{CABG}$ & $\begin{array}{l}\text { Aortic root aneurysm, } \\
\text { chronic type A } \\
\text { dissection }\end{array}$ & $\begin{array}{l}\text { Modified Bentall+ } \\
\text { redo-CABG }\end{array}$ & 67 & $407 / 19$ & 244 & $\begin{array}{l}\text { IABP; CVVHDF; } \\
\text { MOF }\end{array}$ \\
\hline
\end{tabular}

$\overline{C P B}$, Cardiopulmonary bypass; $A V R$, aortic valve replacement; $T V P$, tricuspid valve plasty; $C A B G$, coronary artery bypass grafting; $I A B P$, intraaortic balloon pump; $C V V H D F$, continuous veno-venous hemodiafiltration; $M O F$, multiorgan failure.

artery bypass grafting (case 4). Patients 1, 2, and 3 recovered and were discharged on mean postoperative day 14. At 1year mean follow-up, patients surviving the operation are in good clinical condition, and there has been no case of malfunction of the spared aortic prosthesis; there have been no cases of peripheral embolization or thrombus formation at the site of the tube-valve anastomosis.

Table 2 takes into comparison the intraoperative and early outcome characteristics of the 4 patients who received the prosthesis-sparing operation (group A) versus the individuals who had their valvular prosthesis removed at redo-Bentall (group B). There were no statistically significant differences between the groups in terms of age at reoperation, time between implantation of the aortic valve prosthesis and reoperation, and early outcome (operative mortality). Cardiopulmonary bypass and crossclamp times were not statistically different between groups, although both tended to be higher in group A. Pannus overgrowth was the leading contraindication to the prosthesis-sparing operation in group B (7/9 cases), followed by paravalvular leak in 2 cases.

TABLE 2. Comparison of the intraoperative characteristics of the patients who underwent the prosthesis-sparing operation (group A) versus those who had their valvular prosthesis removed at redoBentall (group B)

\begin{tabular}{lccc}
\hline \multicolumn{1}{c}{ Characteristic } & Group A $(\mathbf{n}=\mathbf{4})$ & Group B $(\mathbf{n}=\mathbf{9})$ & $\boldsymbol{P}$ \\
\hline Age at reoperation (y) & $66.5 \pm 5.4$ & $61.22 \pm 11.5$ & .28 \\
Time between AVR and & $11.2 \pm 4.8$ & $9.3 \pm 5.1$ & .53 \\
$\quad$ reoperation (y) & & & \\
CPB time (min) & $259.5 \pm 100$ & $193.2 \pm 40.1$ & .10 \\
Crossclamp time (min) & $171 \pm 50.4$ & $118.8 \pm 35.3$ & .12 \\
Operative mortality & $25 \%$ & $15.4 \%$ & .99 \\
\hline
\end{tabular}

$A V R$, Aortic valve replacement; $C P B$, cardiopulmonary bypass.
Data are presented as mean \pm standard deviation or as percentages. Intergroup comparison was performed by 2tailed Student $t$ test (continuous data) or chi-square test (categoric data). The alpha level was .05.

\section{DISCUSSION}

Previous reports have suggested the feasibility of a prosthesis-sparing operation. ${ }^{4}$ We underline the potentials of this technique to facilitate the reintervention and to be performed with acceptable blood loss. ${ }^{5}$ Removal of the aortic prosthesis involves operating on a sometimes weakened and traumatized aortic annulus, carrying an increased risk of injury of the adjacent structures or inadequate hemostasis at a surgical site where off-pump repair can be problematic. Distortion of the anatomic proportions of the annulus after the removal of

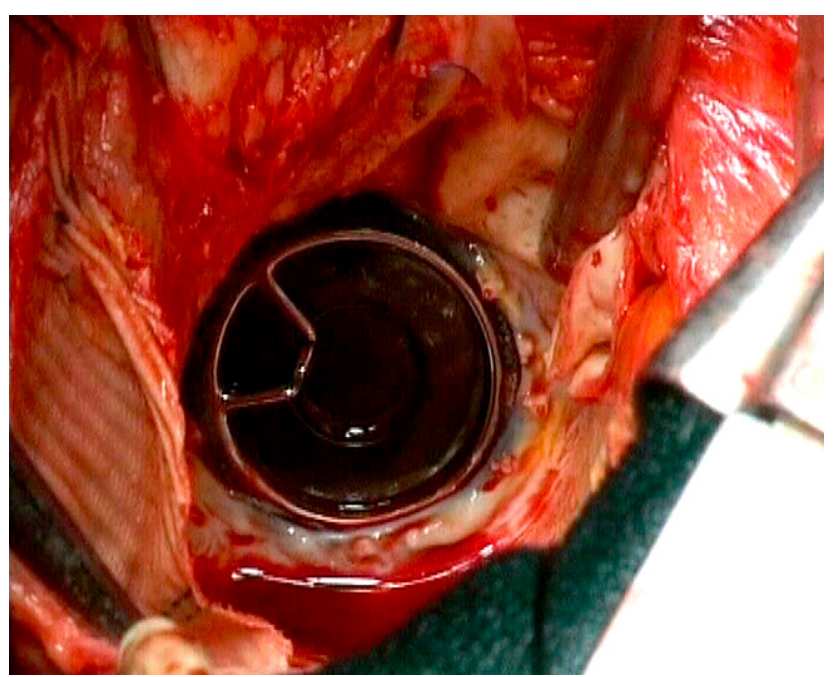

FIGURE 2. Intraoperative view of case 3. A well-functioning single tilting-disc prosthesis is inspected and can be spared. 
the prosthesis may force the surgeon to implant a new valve with a smaller diameter. Whenever possible, leaving the previous prosthesis in place overcomes both shortcomings. However, a dead space may be left in the internal aspect of the tube graft at the site of anastomosis with the prosthetic sewing ring if the sutures are kept too far away from the pyrolytic carbon ring. Turbulence may develop in this area and theoretically give rise to thrombus formation and embolism. Nonetheless, in our series we have not observed thrombosis at postoperative echocardiography or embolic events during follow-up. The anticoagulation regimen required in the presence of the mechanical prosthesis is probably enough to prevent such complication. In addition, the prosthesis-sparing operation can accommodate anatomic variations, such as different heights of the coronary ostia.

All patients presenting to the Division of Cardiac Surgery at Catholic University for aortic root \pm ascending aortic disease after AVR were evaluated for eligibility for the prosthesis-sparing procedure. Among 13 candidates, 4 $(30 \%)$ actually underwent the procedure. This underlines that the candidates for such an approach must be accurately selected; pannus overgrowth is frequent in these patients and represented the most frequent contraindication to the prosthesis-sparing operation in our series. To this issue, we underscore the importance of accurate evaluation of the prosthesis even on the ventricular side by means of intraoperative transesophageal echocardiography while the heart is still beating. Our experience indicates that a well-functioning aortic prosthesis may be spared whenever possible at the time of aortic root replacement, regardless of the time elapsed after the first operation, which does not represent per se a criterion to reject the prosthesis-sparing operation: In the present series (case 3 ) even a single tilting-disc prosthesis was spared (Figure 2), and the mean time elapsed between aortic valve replacement and redo operation was not different between groups. The longest follow-up available in group A is 2 years; the 2 patients who underwent operation in February 2007 are in good clinical condition, and their examination results showed a well-functioning aortic valvular prosthesis. No anastomosis-related complications (ie, pseudoaneurysm) were disclosed. Continued follow-up is in any case necessary. As an additional advantage, the prosthesis-sparing operation may be cost-saving because a simple tube graft is implanted rather than a valved conduit. Our data do not allow us to conclude whether the prosthesis-sparing operation is also time-saving. Cardiopulmonary and myocardial ischemia times were not statistically different between groups, although they tended to be longer in group A. Regardless, one should take into account that concomitant arch replacement with antegrade cerebral perfusion plus tricuspid valve plasty was performed in 1 case and concomitant coronary artery bypass grafting was performed in 1 case. Concomitant procedures have contributed to prolonged operation times.

\section{CONCLUSIONS}

In light of the technical advantages and good results, all patients presenting with aortic root \pm ascending aortic aneurysm after AVR should be evaluated for the prosthesissparing operation.

The authors thank Emanuela Mascarino for invaluable help in the preparation of the illustrations.

\section{References}

1. Vallely MP, Hughes CF, Bannon PG, Hendel PN, French BG, Bayfield MS Composite graft replacement of the aortic root after previous cardiac surgery: a 20-year experience. Ann Thorac Surg. 2000;70:851-5.

2. Matthias Kirsch EW, Radu C, Mekontso-Dessap A, Hillion ML, Loisance D. Aortic root replacement after previous surgical intervention on the aortic valve, aortic root, or ascending aorta. $J$ Thorac Cardiovasc Surg. 2006;131:601-8.

3. Schepens M, Dossche KM, Morshuis WJ. Reoperations on the ascending aorta and aortic root: pitfalls and results in 134 patients. Ann Thorac Surg. 1999;68: 1676-80.

4. Pacini D, Villa E, Martin-Suarez S, Di Bartolomeo R. Aortic root substitution after aortic valve replacement: a prosthesis-sparing operation. Eur J Cardiothorac Surg. 2005;717-9.

5. Yoshikai M, Ito T, Ohnishi H, Kamohara K, Fumoto H, Furutachi A. A safer technique of aortic root replacement after aortic valve replacement. Surg Today. 2006; 36:201-3. 